\title{
Matrine induces mitochondrial apoptosis in cisplatin-resistant non-small cell lung cancer cells via suppression of $\beta$-catenin/survivin signaling
}

\author{
HUAN-QIN WANG, JIAN-JUN JIN and JING WANG \\ Department of Respiratory Medicine, The First Affiliated Hospital, Zhengzhou University, \\ Zhengzhou, Henan 450003, P.R. China
}

Received October 29, 2014; Accepted January 26, 2015

DOI: $10.3892 / o r .2015 .3844$

\begin{abstract}
Matrine is an alkaloid isolated from Sophora flavescens and shows anticancer activities. The present study was carried out to determine the cytotoxic effects of matrine on cisplatin-resistant non-small cell lung cancer (NSCLC) cells and the associated molecular mechanisms. Parental and cisplatin-resistant A549 and H460 NSCLC cells were treated with 1 or $2 \mathrm{~g} / \mathrm{l}$ of matrine for $48 \mathrm{~h}$, and cell viability and apoptosis were assessed. $\beta$-catenin-mediated transcriptional activity, mitochondrial membrane potential $(\Delta \Psi \mathrm{m})$ changes, activation of caspases, and survivin expression were examined. The effect of overexpression of survivin on the anticancer activity of matrine was investigated. Compared to the parental cells, cisplatin-resistant NSCLC cells showed increased $\beta$-catenin transcriptional activity. Matrine treatment resulted in a significant reduction in $\beta$-catenin activation and survivin expression in the cisplatin-resistant cells. Matrine caused apoptotic death in the cisplatin-resistant NSCLC cells, coupled with loss of $\Delta \Psi \mathrm{m}$ and activation of caspase-9 and -3. Matrine-induced apoptosis of the cisplatin-resistant NSCLC cells was significantly reversed by overexpression of survivin. In conclusion, matrine exposure induces mitochondrial apoptosis in cisplatin-resistant NSCLC cells, which is largely mediated through inactivation of $\beta$-catenin/survivin signaling. Further investigation of the therapeutic benefit of matrine in overcoming cisplatin resistance in NSCLC is warranted.
\end{abstract}

\section{Introduction}

Non-small cell lung cancer (NSCLC) accounts for 85\% of all lung cancers and is the leading cause of cancer-related

Correspondence to: Dr Jing Wang, Department of Respiratory Medicine, The First Affiliated Hospital, Zhengzhou University, Zhengzhou, Henan 450003, P.R. China

E-mail: wangjing2012k@163.com

Key words: anticancer therapy, $\beta$-catenin signaling, matrine, mitochondrial apoptotic pathway, drug resistance mortality worldwide (1). Surgery is currently the most effective treatment for early NSCLC (2). However, most NSCLC patients are inoperable due to advanced disease, and are managed with systemic therapies $(3,4)$. Cisplatin-based palliative chemotherapy has been commonly used in patients with advanced NSCLC, yielding a slight survival benefit $(5,6)$. Development of drug resistance is regarded as a major cause for chemotherapy failure in the treatment of cancer (7). Therefore, establishment of effective approaches to overcome cisplatin chemoresistance is of paramount importance in the management of unresectable NSCLC.

The anticancer activity of cisplatin involves the generation of DNA lesions followed by the activation of the DNA damage response and the induction of mitochondrial apoptosis. Numerous mechanisms are responsible for the development of cisplatin resistance, including reduced drug uptake, accelerated drug inactivation, increased DNA damage repair and inhibition of transmission of DNA damage recognition signals to the apoptotic pathway (8). It has been documented that oncogenic $\beta$-catenin signaling plays a critical role the acquisition of cisplatin resistance in NSCLC cells (9). Glycogen synthase kinase $3 \beta$ (GSK3 $\beta$ ) is a multifunctional serine/threonine protein kinase that acts as a negative regulator of $\beta$-catenin signaling (10). GSK3 $\beta$ is activated upon phosphorylation at Tyr216, which leads to phosphorylation and degradation of $\beta$-catenin (11). In contrast, phosphorylation of GSK $3 \beta$ at Ser9 inhibits its ability to promote the degradation of $\beta$-catenin (12). Inactivation of GSK $3 \beta$ results in the translocation of active $\beta$-catenin to the nucleus, where it interacts with the transcription factor Tcf/Lef to activate multiple pro-proliferative and survival genes such as c-Myc, cyclin D1 and survivin (13). The $\beta$-catenin pathway has been suggested as an attractive target pathway for improving the susceptibility of cancer cells to cisplatin $(14,15)$.

Matrine is an alkaloid isolated from Sophora flavescens and possesses multiple biological activities including antiinflammatory (16), antiviral (17) and antitumor (18) activities. Different molecular pathways mediate the cytotoxic effects of matrine on tumor cells $(19,20)$. For instance, Niu et al (19) reported that matrine induces apoptosis of lung cancer cells through inhibition of Akt signaling. Downregulation of the ERK-NF- $\kappa \mathrm{B}$ pathway is causally linked to the inhibition of 
human osteosarcoma cell invasion by matrine (20). In Hep3B hepatoma cells, matrine has been shown to decrease $\beta$-catenindependent transcriptional activity (21). Given the involvement of the $\beta$-catenin pathway in cisplatin resistance in NSCLC cells, we hypothesized that matrine could sensitizes NSCLC cells to cisplatin through inactivation of $\beta$-catenin signaling.

Therefore, in the present study, we attempted to explore the cytotoxic effects of matrine on cisplatin-resistant NSCLC cells and to ascertain whether the anticancer activity of matrine is mediated through modulation of $\beta$-catenin signaling.

\section{Materials and methods}

Cell lines. Two human NSCLC cell lines A549 and H460 were purchased from the American Type Culture Collection (ATCC; Rockville, MD, USA) and cultured in Dulbecco's modified Eagle's medium (DMEM) supplemented with $10 \%$ fetal bovine serum (FBS), $100 \mathrm{U} / \mathrm{ml}$ penicillin and $100 \mu \mathrm{g} / \mathrm{ml}$ streptomycin (Invitrogen, Carlsbad, CA, USA).

In accordance with previously described methods (23), cisplatin (CDDP)-resistant sublines A549/CDDP and H460/CDDP were established by continuous exposure of the parental cells to increasing concentrations of cisplatin, ranging from $2 \mathrm{nM}$ to $4 \mu \mathrm{M}$ for $>6$ months. The drug-resistant cell lines were maintained in DMEM containing $4 \mu \mathrm{M}$ cisplatin.

Matrine treatment. A549/CDDP and H460/CDDP and their parental cells were seeded at $4-6 \times 10^{4}$ cells/well onto 12 -well plates and cultured overnight to allow attachment. The cells were exposed to 1 or $2 \mathrm{~g} / \mathrm{l}$ of matrine (Sigma, St. Louis, MO, USA) for $48 \mathrm{~h}$. After treatment, the cells were subjected to gene expression and apoptosis analysis.

Plasmid transfection. Human survivin-expressing plasmid (pcDNA3.1-survivin) was kindly provided by Dr Altieri (University of Massachusetts, Worcester, MA, USA). Cells were seeded at a density of $3 \times 10^{5}$ cells/well onto 6 -well plates and pre-transfected with empty vector or pcDNA3.1-survivin using Lipofectamine 2000. The transfection efficiency was $\sim 70 \%$, which was determined by transfection of a green fluorescent protein-expressing plasmid (pGFP-N1; Clontech, Mountain View, CA, USA). After incubation for $24 \mathrm{~h}$, the transfected cells were exposed to matrine for an additional $48 \mathrm{~h}$ before apoptosis analysis.

Cell viability assay. Cells were seeded onto 96-well plates at $3 \times 10^{3}$ cells/well and cultured overnight to allow adherence. Different concentrations of cisplatin (i.e., 0.5, 1, 2, 4, 8, 16, 32 and $64 \mu \mathrm{M})$ were added to the cell culture. After incubation for $48 \mathrm{~h}$, cell viability was assessed using the 3-(4,5-dimethylthiazol-2-yl)-2,5-diphenyltetrazolium bromide (MTT) assay. MTT solution ( $5 \mathrm{mg} / \mathrm{ml}$ ) (Sigma) was added to each well and incubated for $4 \mathrm{~h}$. After removal of the MTT solution, formazan crystals were dissolved in dimethyl sulfoxide. The absorbance was measured at a wavelength of $570 \mathrm{~nm}$. The $50 \%$ inhibitory concentration $\left(\mathrm{IC}_{50}\right)$ was calculated from the survival curve.

Western blot analysis. Primary antibodies used in the present study are as follows: anti- $\beta$-catenin (\#9562), anti-phospho$\beta$-catenin (Ser33/37/Thr41) (\#9561), anti-non-phospho (active) $\beta$-catenin (Ser33/37/Thr41) (\#4270), anti-GSK-3 $\beta$ (\#9315), anti-phospho-GSK-3 $\beta$ (Ser9) (\#9323) (Cell Signaling Technology, Danvers, MA, USA), anti-survivin (sc-10811) and anti- $\beta$-actin (sc-130301) (Santa Cruz Biotechnology, Santa Cruz, CA, USA).

Following treatment, the cells were lysed in radioimmunoprecipitation assay (RIPA) buffer [150 mM NaCl, $1 \%$ NP40, $0.5 \%$ deoxycholic acid, $0.1 \%$ sodium dodecylsulfate (SDS), $50 \mathrm{mM}$ Tris- $\mathrm{HCl}$ (pH 8.0)] supplemented with protease and phosphatase inhibitors. The protein samples were separated on polyacrylamide gels and then transferred to a nitrocellulose membrane. After blocking for $1 \mathrm{~h}$ in a Tris-buffered solution (TBS) containing 5\% fat-free dried milk and 0.5\% Tween-20, the membrane was incubated with individual primary antibodies overnight at $4^{\circ} \mathrm{C}$. The membrane was washed three times and incubated for $1 \mathrm{~h}$ with horseradish peroxidase-conjugated secondary antibodies (Santa Cruz Biotechnology). The signals were visualized with an enhanced chemiluminescence detection kit (Amersham Pharmacia Biotech, Piscataway, NJ, USA). Densitometric analysis of the protein bands was performed using the Quantity One software (Bio-Rad, Hercules, CA, USA).

Luciferase reporter gene assay. A $\beta$-catenin/TCF firefly luciferase reporter construct (pTopFlash) was purchased from Upstate Biotechnology (Waltham, MA, USA). A control pRL-TK reporter plasmid encoding Renilla luciferase was purchased from Promega (Madison, WI, USA). Cells were seeded onto 12 -well plates at $6 \times 10^{4}$ cells/well and transiently transfected with $0.2 \mu \mathrm{g}$ of pTopFlash along with $0.02 \mu \mathrm{g}$ pRL-TK using Lipofectamine 2000 (Invitrogen) following the manufacturer's protocol. Cells were collected $24 \mathrm{~h}$ post-transfection or treated with matrine for $48 \mathrm{~h}$ before collection. The cells were then lysed and centrifuged and the supernatant was obtained for measurement of luciferase activities using the Dual-Luciferase Assay System (Promega). The firefly luciferase activity was normalized to Renilla luciferase activity and expressed as relative luciferase activity.

Apoptosis detection by Annexin V/PI staining. After drug treatment, the cells were trypsinized and centrifuged. The cell pellet was resuspended and incubated with $1 \mu \mathrm{l}$ of fluorescein isothiocyanate (FITC)-conjugated Annexin V and $5 \mu \mathrm{l}$ of propidium iodide (PI) (Becton-Dickinson Biosciences, San Diego, CA, USA) for $15 \mathrm{~min}$ at $4^{\circ} \mathrm{C}$ in the dark. Apoptotic cells were analyzed on a FACSCalibur flow cytometer using CellQuest software (Becton-Dickinson Biosciences).

Mitochondrial membrane potential $(\Delta \Psi \mathrm{m})$ assay. $\Delta \Psi \mathrm{m}$ was measured using the JC-1 mitochondrial membrane potential assay kit (Biotium, Hayward, CA, USA). When $\Delta \Psi \mathrm{m}$ is relatively low, the cyanine dye JC-1 (5,5',6,6'-tetrachloro1,1',3,3'-tetraethylbenzimi-dazolylcarbocyanine iodide) localizes in the cytoplasm in a green fluorescent monomeric form. At a high $\Delta \Psi \mathrm{m}$, the JC-1 dye aggregates and yields red fluorescence. A decrease in the ratio of the red/green fluorescence indicates loss of $\Delta \Psi \mathrm{m}$. In brief, cells were harvested after drug treatment and stained with $10 \mathrm{mM} \mathrm{JC}-1$ at $37^{\circ} \mathrm{C}$ for $15 \mathrm{~min}$ in the dark. Cells were washed and green/red fluorescence was analyzed by flow cytometry. 

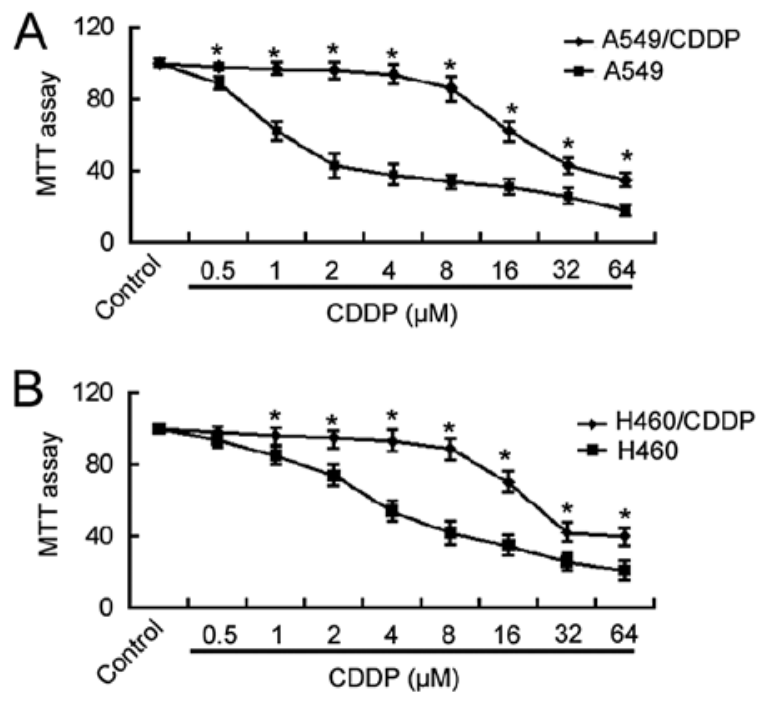

Figure 1. Assessment of the susceptibility to cisplatin (CDDP) in CDDPresistant and parental cells. CDDP-resistant (A) A549 and (B) H460 cells and their parental cells were treated with a series of concentrations of CDDP for $48 \mathrm{~h}$, and cell viability was assessed using the MTT method. ${ }^{*} \mathrm{P}<0.05$ vs. the parental cells.

Measurement of caspase-9 and -3 activities. Measurement of cellular caspase- 9 and -3 activities was carried out using the caspase- 3 and -9 activity kits (Beyotime, Haimen, Jiangsu, China) according to the manufacturer's instructions. Briefly, cells were collected after drug treatment, washed and lysed in lysis buffer on ice for $10 \mathrm{~min}$. Cell lysates were incubated at $37^{\circ} \mathrm{C}$ for $4 \mathrm{~h}$ with $1 \mathrm{X}$ reaction buffer containing a caspase- 3 substrate (acetyl-Asp-Glu-Val-Asp-p-nitroanilide) or caspase-9 substrate (acetyl-Leu-Glu-His-Asp-p-nitroanilide). Caspase activities were measured by spectrofluorometry.

Statistical analysis. All data are expressed as mean \pm standard deviation (SD). Statistical significance was analyzed using the Student's t-test or one-way analysis of variance with Tukey's post-hoc test. A difference was defined as significant at $\mathrm{P}<0.05$.

\section{Results}

Activation of $\beta$-catenin signaling is associated with acquisition of cisplatin resistance. Cisplatin-resistant A549 cells were generated by culturing cells in gradually increasing concentrations of cisplatin. The MTT assay revealed that the $\mathrm{IC}_{50}$ value of A549/CDDP cells for cisplatin was $~ 15$-fold higher than that of the parental A549 cells (24.7 \pm 1.5 vs. $1.6 \pm 0.2 \mu \mathrm{M}$; Fig. 1A). Similarly, H460/CDDP cells showed an $\sim 6$-fold increase in the $\mathrm{IC}_{50}$ value for cisplatin compared to the parental cells $(28.3 \pm 1.2$ vs. $4.6 \pm 0.4 \mu \mathrm{M}$; Fig. 1B). These results indicate the acquisition of cisplatin resistance in NSCLC cells following long-term exposure to cisplatin.

Western blot analysis identified a marked increase in non-phospho (active) $\beta$-catenin (Ser33/37/Thr41) and total $\beta$-catenin protein in the cisplatin-resistant NSCLC cells relative to the parental cells (Fig. 2A). To evaluate the changes in $\beta$-catenin transcriptional activity, cells were transiently transfected with the $\beta$-catenin luciferase reporter plasmid. We

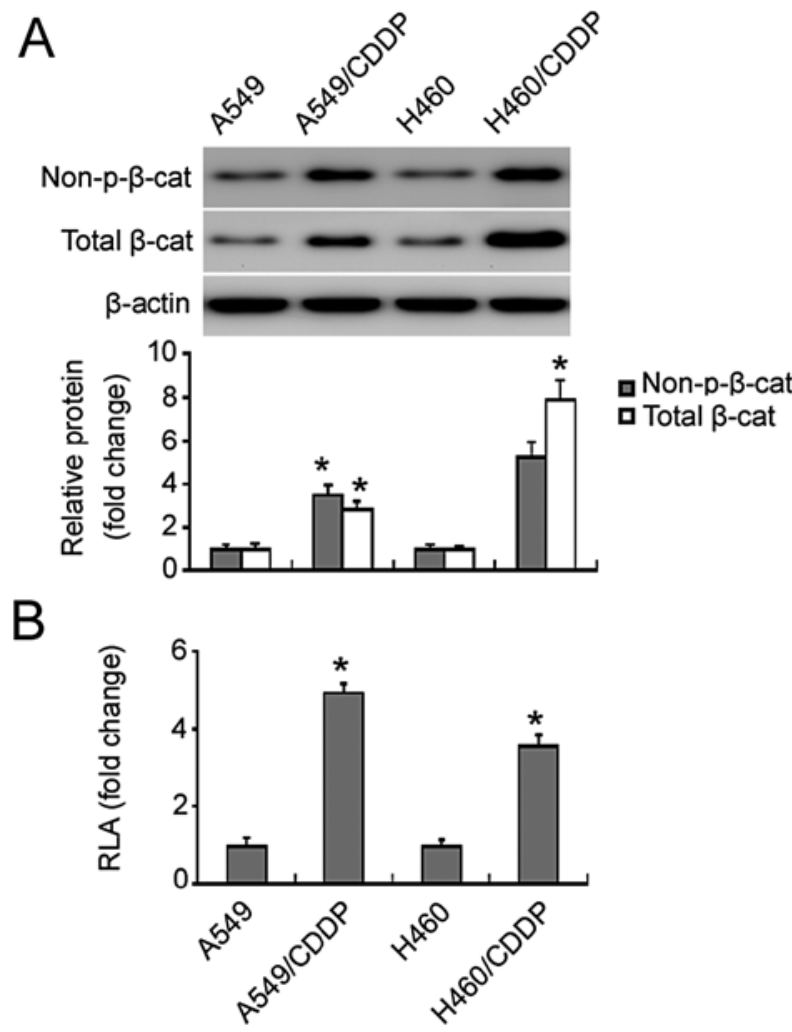

Figure 2. Increased $\beta$-catenin activity in the CDDP-resistant NSCLC cells (A) Western blot analysis of total and non-phospho (active) $\beta$-catenin (non$\mathrm{p}$ - $\beta$-cat). Representative blots are shown in the top panels, and densitometric quantification of the blots is shown in the bottom graph. (B) CDDP-resistant A549 and H460 cells and their parental cells were transfected with pTopFlash and pRL-TK. After incubation for $24 \mathrm{~h}$, the cells were treated with matrine for an additional $48 \mathrm{~h}$. The cells were collected and tested for luciferase activities. The results are expressed as relative luciferase activity (RLA) compared to the parental cells arbitrarily assigned as $1 .{ }^{*} \mathrm{P}<0.05$ vs. the untreated cells. CDDP, cisplatin; NSCLC, non-small cell lung cancer.

found that there was a 3.5- and 5-fold increase in the $\beta$-catenin reporter activity in the cisplatin-resistant H460 and A549 cells relative to the parental cells, respectively (Fig. 2B).

Matrine suppresses $\beta$-catenin signaling in the cisplatinresistant NSCLC cells. Next, we explored the effect of matrine on $\beta$-catenin signaling in the cisplatin-resistant cells. As shown in Fig. 3A and B, matrine treatment reduced the Ser33/37/Thr41-unphosphorylated active $\beta$-catenin protein level in the cisplatin-resistant cells. Moreover, matrine exposure resulted in a marked decrease in the phosphorylated level of GSK3 $\beta$ (Ser9) and increase in the total level of GSK3 $\beta$ protein (Fig. 3A and B). The $\beta$-catenin luciferase reporter assay confirmed a significant decrease in the $\beta$-catenin-mediated transcriptional activity in matrine-treated cisplatin-resistant cells (Fig. 3C). Additionally, survivin, a target gene of $\beta$-catenin, was downregulated by matrine exposure (Fig. 3D).

Matrine induces apoptosis in cisplatin-resistant cells via the mitochondrial death pathway. Flow cytometric analysis revealed that matrine at $2 \mathrm{~g} / 1$ significantly induced apoptosis in the A549/CDDP and H460/CDDP cells, with a 5-8-fold increase in the apoptosis rates relative to the untreated cells (Fig. 4A). Matrine-induced apoptosis was accompanied by a marked loss 
A

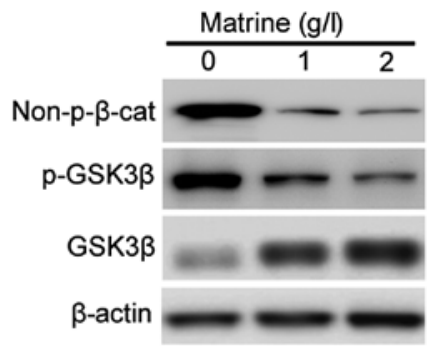

C

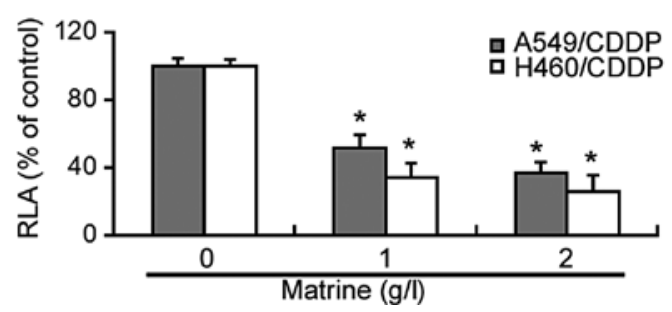

B

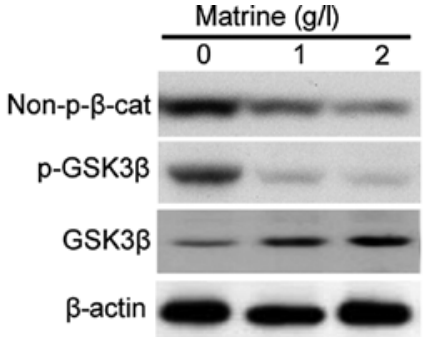

D

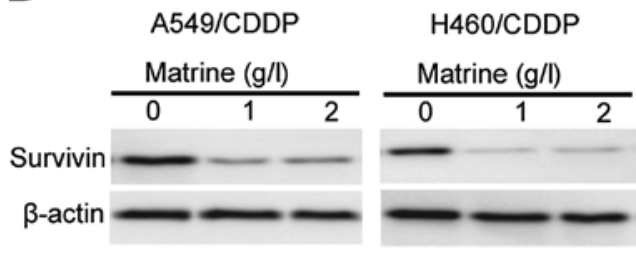

Figure 3. Effect of matrine treatment on $\beta$-catenin signaling in CDDP-resistant NSCLC cells. CDDP-resistant (A) A549 and (B) H460 cells were untreated or treated with 1 or $2 \mathrm{~g} / \mathrm{l}$ of matrine for $48 \mathrm{~h}$, and western blot analysis was carried out to analyze changes in $\beta$-catenin signaling. Representative blots are shown. non-p- $\beta$-Cat, non-phospho $\beta$-catenin. (C) CDDP-resistant A549 and H460 cells were pre-transfected with pTopFlash and pRL-TK and $24 \mathrm{~h}$ later, treated with or without matrine for an additional $48 \mathrm{~h}$. The results are expressed as relative luciferase activity (RLA) compared to the control cells (without matrine treatment) arbitrarily assigned as $100 \%$. ${ }^{*} \mathrm{P}<0.05$ vs. the control cells. (D) Western blot analysis of survivin expression in the CDDP-resistant NSCLC cells with or without matrine treatment. CDDP, cisplatin; NSCLC, non-small cell lung cancer.

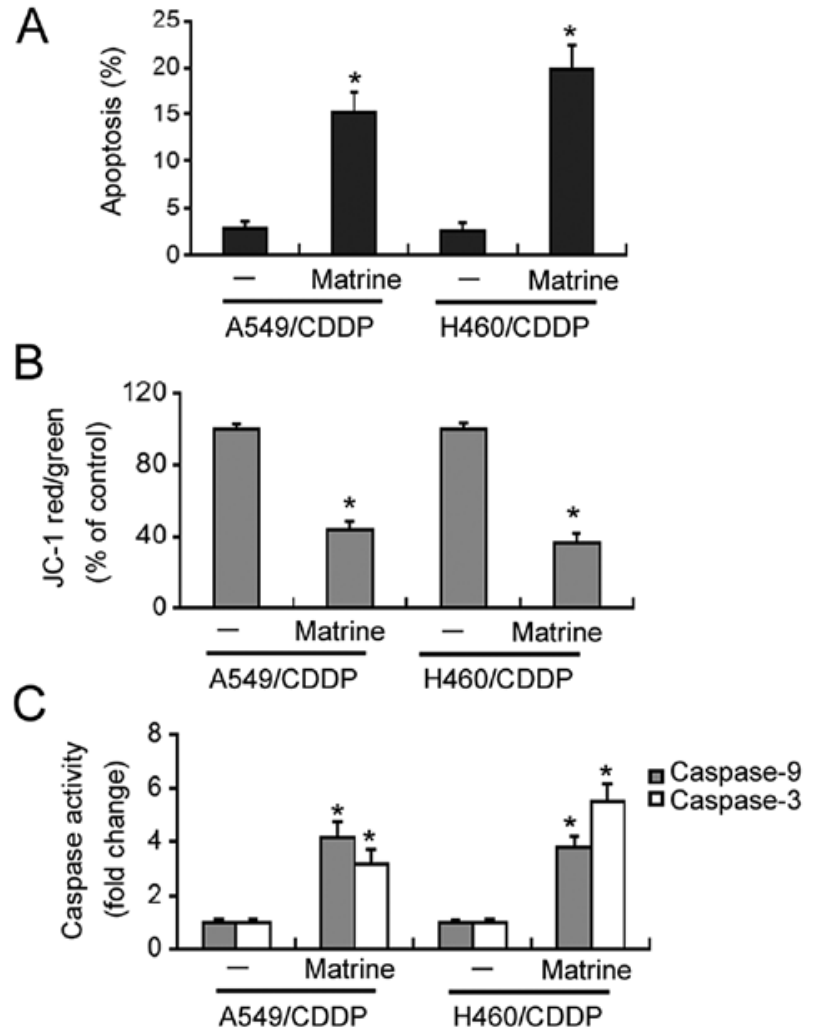

Figure 4. Matrine induces mitochondrial apoptosis in CDDP-resistant NSCLC cells. A549/CDDP and H460/CDDP cells were untreated or treated with $2 \mathrm{~g} / 1$ matrine for $48 \mathrm{~h}$ and apoptotic changes were assessed. (A) Flow cytometric analysis of apoptotic cells stained with Annexin V and PI. Annexin V-positive cells were considered apoptotic. (B) Loss of $\Delta \Psi \mathrm{m}$ was determined by flow cytometry using JC-1 staining. The ratio of the red/green fluorescence was calculated. The results are expressed as a percentage of the control values (assigned 100\%). (C) Measurement of activities of caspase-3 and -9. The relative caspase activity is expressed as fold-change compared to the control cells (assigned 1). ${ }^{*} \mathrm{P}<0.05$ vs. untreated cells. $\Delta \Psi \mathrm{m}$, mitochondrial membrane potential. CDDP, cisplatin; NSCLC, non-small cell lung cancer.

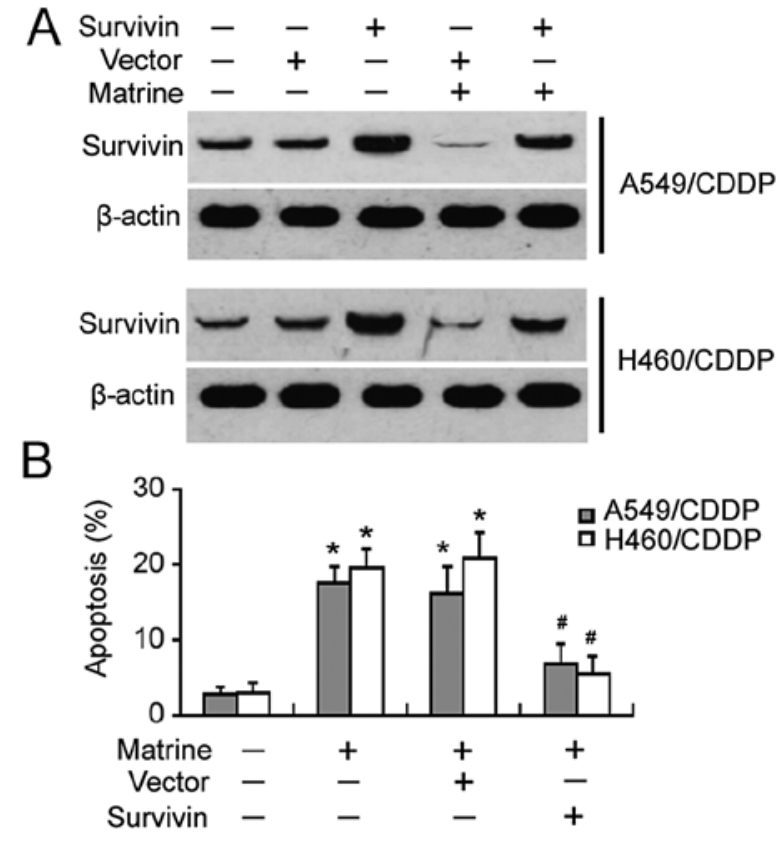

Figure 5. Effect of enforced expression of survivin on matrine-induced apoptosis. (A) Western blot analysis of survivin expression in the A549/CDDP and H460/CDDP cells transfected with the control vector or survivin-expressing plasmid after exposure to $2 \mathrm{~g} / \mathrm{l}$ matrine for $48 \mathrm{~h}$. Representative blots of three independent experiments are shown. (B) A549/CDDP and H460/CDDP cells were treated with $2 \mathrm{~g} / 1$ matrine or pre-transfected with the control vector or survivin-expressing plasmid before matrine treatment. After incubation for $48 \mathrm{~h}$, the cells were subjected to apoptosis detection using Annexin V and PI staining. ${ }^{~} \mathrm{P}<0.05$ vs. the untreated cells; ${ }^{~} \mathrm{P}<0.05$ vs. matrine alone. $\mathrm{CDDP}$ cisplatin.

in $\Delta \Psi \mathrm{m}$ (Fig. 4B). Moreover, both caspase-9 and -3 activities were significantly increased in the matrine-treated cisplatinresistant cells, compared to the untreated cells (Fig. 4C). 
Ectopic expression of survivin protects against matrineinduced apoptosis. To determine the role of survivin in matrine-induced apoptosis of cisplatin-resistant NSCLC cells, the cells were pre-transfected with the survivin-expressing plasmid before exposure to matrine. Western blot analysis confirmed that the expression level of survivin remained high after matrine treatment in survivin-transfected cells, yet was markedly reduced in vector-transfected cells (Fig. 5A). After a 48-h incubation with matrine, apoptotic death was significantly observed in the vector-transfected cells, yet not in the survivin-transfected cells (Fig. 5B). These results indicate that survivin can rescue cisplatin-resistant cells from matrineinduced apoptosis.

\section{Discussion}

Aberrant activation of $\beta$-catenin signaling is causally linked to the development of resistance to anticancer drugs (24). It has been reported that miR-29a-induced resistance to gemcitabine in pancreatic cancer cells is mediated through activation of the $\mathrm{Wnt} / \beta$-catenin signaling pathway (25). In contrast, inhibition of $\mathrm{Wnt} / \beta$-catenin signaling reverses multidrug resistance in cholangiocarcinoma cells (26). A previous study showed that inhibition of cytoplasmic GSK3 $\beta$ in A549/CDDP cells leads to activation of $\mathrm{Wnt} / \beta$-catenin signaling, consequently increasing cisplatin resistance (9). In line with these studies, our data demonstrated that the acquisition of cisplatin resistance in NSCLC cells after chronic exposure to cisplatin was associated with elevated $\beta$-catenin activity. Downregulation of $\beta$-catenin via RNA interference technology reversed drug resistance in A549/CDDP cells (27), confirming the essential role for $\beta$-catenin activity in cisplatin resistance in NSCLC cells.

Matrine has been shown to inhibit $\beta$-catenin signaling in hepatoma cells (22). However, in WB-F344 rat liver epithelial stem-like cells, matrine has been found to induce $\beta$-catenin activation (21). Our data provide initial evidence that matrine treatment led to impaired $\beta$-catenin activation in cisplatin-resistant NSCLC cells. These findings suggest that the regulatory effects of matrine on $\beta$-catenin signaling are cellular context-dependent. GSK3 3 is a pivotal negative regulator of $\beta$-catenin signaling and its phosphorylation at Ser9 decreases its ability to promote $\beta$-catenin degradation (12). We found that matrine-treated cells showed increased total GSK3 $\beta$ protein and reduced Ser9-phosphorylated GSK3 $\beta$ protein, coupled with reduced $\beta$-catenin-dependent transcriptional activity. These results indicate that upregulation of GSK3 $\beta$ accounts for matrine-mediated inactivation of $\beta$-catenin in cisplatin-resistant NSCLC cells.

Apoptosis induction is an important mechanism for the action of anticancer agents. The proapoptotic activity of matrine has been described in a variety of cancer cells, such as lung cancer (19) and hepatocellular carcinoma cells (28). Our data confirmed that matrine was also able to induce apoptotic death in cisplatin-resistant NSCLC cells. The mitochondrial pathway is an important pathway of apoptosis (29), which involves loss of $\Delta \Psi \mathrm{m}$ and release of several proapoptotic proteins including cytochrome $c$ from the mitochondrial intermembrane space to the cytosol, leading to activation of procaspase- 9 and -3 . Notably, matrine treatment of cisplatin- resistant NSCLC cells resulted in dramatic loss of $\triangle \Psi \mathrm{m}$ and increased caspase- 9 and -3 activities, indicating activation of the mitochondrial death pathway. In agreement with our findings, matrine also induced mitochondrial apoptosis in human acute myeloid leukemia cells (30).

Having identified that matrine suppressed $\beta$-catenin signaling and induced apoptosis in cisplatin-resistant NSCLC cells, we next checked whether inactivation of $\beta$-catenin signaling is causally linked to the proapoptotic activity of matrine. It has been documented that activated $\beta$-catenin regulates the transcription of several oncogenic target genes (13). Survivin is an important target gene of $\beta$-catenin and its overexpression induces anticancer drug resistance (31). In NSCLC, survivin expression affects the susceptibility to drug-induced cell apoptosis $(32,33)$. Okamoto et al $(32)$ reported that stable overexpression of survivin attenuated apoptotic death induced by gefitinib, an epidermal growth factor receptor-tyrosine kinase inhibitor. Targeting survivin has been shown to enhance cisplatin sensitivity in lung cancer xenografts (33). Notably, we found that matrine treatment resulted in a significant reduction in survivin expression. Moreover, restoration of survivin counteracted matrine-induced apoptosis in cisplatin-resistant NSCLC cells. These findings highlight an important role for survivin in the regulation of NSCLC cell susceptibility to matrine. Matrine-induced downregulation of survivin has also been described in multiple myeloma cell lines (34). Despite the importance of survivin, we cannot exclude the possibility that other target genes of $\beta$-catenin may have an impact on the anticancer activity of matrine in NSCLC cells.

In conclusion, matrine has the capacity to induce mitochondrial apoptosis in cisplatin-resistant NSCLC cells, which is associated with inactivation of $\beta$-catenin/survivin signaling. Therefore, matrine represents a novel anticancer agent for overcoming cisplatin resistance in NSCLC.

\section{References}

1. Herbst RS, Heymach JV and Lippman SM: Lung cancer. N Engl J Med 359: 1367-1380, 2008.

2. Howington JA, Blum MG, Chang AC, Balekian AA and Murthy SC: Treatment of stage I and II non-small cell lung cancer: diagnosis and management of lung cancer, 3rd ed: American College of Chest Physicians evidence-based clinical practice guidelines. Chest 143 (Suppl 5): e278S-e313S, 2013.

3. Peters S, Zimmermann S and Adjei AA: Oral epidermal growth factor receptor tyrosine kinase inhibitors for the treatment of non-small cell lung cancer: comparative pharmacokinetics and drug-drug interactions. Cancer Treat Rev 40: 917-926, 2014.

4. Krzakowski M, Lucas C and Gridelli C: Fractionated scheme of oral vinorelbine as single-agent therapy or in combination with cisplatin concomitantly with thoracic radiotherapy in stage III non-small-cell lung cancer: dose-escalation phase I trial. Clin Lung Cancer 15: 266-273, 2014.

5. Ardizzoni A, Boni L, Tiseo M, et al: Cisplatin-versus carboplatin-based chemotherapy in first-line treatment of advanced non-small-cell lung cancer: an individual patient data metaanalysis. J Natl Cancer Inst 99: 847-857, 2007.

6. D'Addario G, Pintilie M, Leighl NB, Feld R, Cerny T and Shepherd FA: Platinum-based versus non-platinum-based chemotherapy in advanced non-small-cell lung cancer: a metaanalysis of the published literature. J Clin Oncol 23: 2926-2936, 2005 .

7. Rosell R, Lord RV, Taron M and Reguart N: DNA repair and cisplatin resistance in non-small-cell lung cancer. Lung Cancer 38: 217-227, 2002

8. Galluzzi L, Senovilla L, Vitale I, Michels J, Martins I, Kepp O, Castedo M and Kroemer G: Molecular mechanisms of cisplatin resistance. Oncogene 31: 1869-1883, 2012. 
9. Gao Y,Liu Z, Zhang X,He J,Pan Y,Hao F, Xie L, Li Q, Qiu X and Wang E: Inhibition of cytoplasmic GSK-3 $\beta$ increases cisplatin resistance through activation of $\mathrm{Wnt} / \beta$-catenin signaling in A549/DDP cells. Cancer Lett 336: 231-239, 2013.

10. Doble BW and Woodgett JR: GSK-3: tricks of the trade for a multi-tasking kinase. J Cell Sci 116: 1175-1186, 2003.

11. Orford K, Crockett C, Jensen JP, Weissman AM and Byers SW: Serine phosphorylation-regulated ubiquitination and degradation of $\beta$-catenin. J Biol Chem 272: 24735-24738, 1997.

12. Cohen P and Goedert M: GSK3 inhibitors: development and therapeutic potential. Nat Rev Drug Discov 3: 479-487, 2004.

13. Kolligs FT, Bommer G and Göke B: Wnt/beta-catenin/tcf signaling: a critical pathway in gastrointestinal tumorigenesis. Digestion 66: 131-144, 2002.

14. Dvory-Sobol H, Sagiv E, Kazanov D, Ben-Ze'ev A and Arber N: Targeting the active $\beta$-catenin pathway to treat cancer cells. Mol Cancer Ther 5: 2861-2871, 2006.

15. Wei Y, Shen N, Wang Z, Yang G, Yi B, Yang N, Qiu Y and Lu J: Sorafenib sensitizes hepatocellular carcinoma cells to cisplatin via suppression of Wnt/ $\beta$-catenin signaling. Mol Cell Biochem 381: 139-144, 2013.

16. Huang WC, Chan CC, Wu SJ, Chen LC, Shen JJ, Kuo ML, Chen MC and Liou CJ: Matrine attenuates allergic airway inflammation and eosinophil infiltration by suppressing eotaxin and Th2 cytokine production in asthmatic mice. J Ethnopharmacol 151: 470-477, 2014

17. Yang Y, Xiu J, Zhang X, Zhang L, Yan K, Qin C and Liu J: Antiviral effect of matrine against human enterovirus 71 Molecules 17: 10370-10376, 2012.

18. Liu Y, Xu Y, Ji W, Li X, Sun B, Gao Q and Su C: Anti-tumor activities of matrine and oxymatrine: literature review. Tumour Biol 35: 5111-5119, 2014.

19. Niu $\mathrm{H}$, Zhang $\mathrm{Y}$, Wu B, Zhang Y, Jiang $\mathrm{H}$ and He P: Matrine induces the apoptosis of lung cancer cells through downregulation of inhibitor of apoptosis proteins and the Akt signaling pathway. Oncol Rep 32: 1087-1093, 2014

20. Li Y, Zhang ZN, Zhao HM, Tong ZC, Yang J, Wang H and Liang XJ: Matrine inhibits the invasive properties of human osteosarcoma cells by downregulating the ERK-NF- $\kappa$ B pathway. Anticancer Drugs 25: 1035-1043, 2014.

21. Xie BS, He XX, Ai ZL and Yao SK: Involvement of $\beta$-catenin in matrine-induced autophagy and apoptosis in WB-F344 cells. Mol Med Rep 9: 2547-2553, 2014.

22. Guo D, Chen NN, Zhou P, Pan B and Hou LB: Suppressive effect of matrine on cell growth and decreases beta-catenin-dependent transcriptional activity in hepatoma cell line Hep3B. Zhong Yao Cai 33: 778-781, 2010 (In Chinese).
23. Jiang Z, Yin J, Fu W, Mo Y, Pan Y, Dai L, Huang H, Li S and Zhao J: miRNA 17 family regulates cisplatin-resistant and metastasis by targeting TGFbetaR2 in NSCLC. PLoS One 9: e94639, 2014

24. He K, Xu T, Xu Y, Ring A, Kahn M and Goldkorn A: Cancer cells acquire a drug resistant, highly tumorigenic, cancer stem-like phenotype through modulation of the PI3K/Akt/ $\beta$-catenin/CBP pathway. Int J Cancer 134: 43-54, 2014.

25. Nagano H, Tomimaru Y, Eguchi H, Hama N, Wada H, Kawamoto K, Kobayashi S, Mori M and Doki Y: MicroRNA-29a induces resistance to gemcitabine through the $\mathrm{Wnt} / \beta$-catenin signaling pathway in pancreatic cancer cells. Int J Oncol 43: 1066-1072, 2013

26. Shen DY, Zhang W, Zeng X and Liu CQ: Inhibition of Wnt/ $\beta$-catenin signaling downregulates P-glycoprotein and reverses multi-drug resistance of cholangiocarcinoma. Cancer Sci 104: 1303-1308, 2013.

27. Teng Y, Wang X, Wang Y and Ma D: Wnt/ $\beta$-catenin signaling regulates cancer stem cells in lung cancer A549 cells. Biochem Biophys Res Commun 392: 373-379, 2010.

28. Zhou H, Xu M, Gao Y, et al: Matrine induces caspase-independent program cell death in hepatocellular carcinoma through bid-mediated nuclear translocation of apoptosis inducing factor. Mol Cancer 13: 59, 2014.

29. Green DR and Kroemer G: The pathophysiology of mitochondrial cell death. Science 305: 626-629, 2014.

30. Zhang S, Zhang Y, Zhuang Y, Wang J, Ye J, Zhang S, Wu J, Yu K and Han Y: Matrine induces apoptosis in human acute myeloid leukemia cells via the mitochondrial pathway and Akt inactivation. PLoS One 7: e46853, 2012.

31. Cheung CH, Huang CC, Tsai FY, et al: Survivin - biology and potential as a therapeutic target in oncology. Onco Targets Ther 6: 1453-1462, 2013

32. Okamoto K, Okamoto I, Okamoto W, Tanaka K, Takezawa K, Kuwata K, Yamaguchi H, Nishio K and Nakagawa K: Role of survivin in EGFR inhibitor-induced apoptosis in non-small cell lung cancers positive for EGFR mutations. Cancer Res 70: 10402-10410, 2010.

33. Tian H, Liu S, Zhang J, et al: Enhancement of cisplatin sensitivity in lung cancer xenografts by liposome-mediated delivery of the plasmid expressing small hairpin RNA targeting Survivin. J Biomed Nanotechnol 8: 633-641, 2012.

34. Yu Q, Chen B, Zhang X, Qian W, Ye B and Zhou Y: Arsenic trioxide-enhanced, matrine-induced apoptosis in multiple myeloma cell lines. Planta Med 79: 775-781, 2013. 